University of Nebraska - Lincoln

DigitalCommons@University of Nebraska - Lincoln

Agronomy \& Horticulture - Faculty Publications

Agronomy and Horticulture Department

2014

Quantitative Trait Loci (QTL) that Underlie SCN Resistance in Soybean [Glycine max (L.) Merr.] PI438489B by 'Hamilton' Recombinant Inbred Line (RIL) Population

\author{
Kassem My Abdelmajid \\ Fayetteville State University \\ Laura Ramos \\ Southern Illinois University \\ D. L. Hyten \\ Soybean Genomics and Improvement Laboratory, Beltsville, MD, david.hyten@unl.edu \\ Jason Bond \\ Southern Illinois University \\ Abdelhafid Bendahmane \\ Unite de Recherche En Genomique Vegetale, INRA, Ivry, France \\ Follow this and additional works at: https://digitalcommons.unl.edu/agronomyfacpub \\ 2 next page for additional authors \\ Part of the Agricultural Science Commons, Agriculture Commons, Agronomy and Crop Sciences \\ Commons, Botany Commons, Horticulture Commons, Other Plant Sciences Commons, and the Plant \\ Biology Commons
}

Abdelmajid, Kassem My; Ramos, Laura; Hyten, D. L.; Bond, Jason; Bendahmane, Abdelhafid; Arelli, Prakash R.; Njiti, Victor N.; Cianzio, Silvia; Kantartzi, Stella K.; and Meksem, Khalid, "Quantitative Trait Loci (QTL) that Underlie SCN Resistance in Soybean [Glycine max (L.) Merr.] PI438489B by 'Hamilton' Recombinant Inbred Line (RIL) Population" (2014). Agronomy \& Horticulture -- Faculty Publications. 809. https://digitalcommons.unl.edu/agronomyfacpub/809

This Article is brought to you for free and open access by the Agronomy and Horticulture Department at DigitalCommons@University of Nebraska - Lincoln. It has been accepted for inclusion in Agronomy \& Horticulture -Faculty Publications by an authorized administrator of DigitalCommons@University of Nebraska - Lincoln. 


\section{Authors}

Kassem My Abdelmajid, Laura Ramos, D. L. Hyten, Jason Bond, Abdelhafid Bendahmane, Prakash R. Arelli, Victor N. Njiti, Silvia Cianzio, Stella K. Kantartzi, and Khalid Meksem 


\title{
Quantitative Trait Loci (QTL) that Underlie SCN Resistance in Soybean [Glycine max (L.) Merr.] PI438489B by 'Hamilton' Re- combinant Inbred Line (RIL) Population
}

\author{
Kassem My Abdelmajid', Laura Ramos ${ }^{2}$, David Hyten ${ }^{3}$, Jason Bond ${ }^{2}$, Abdelhafid Bendahmane ${ }^{4}$, \\ Prakash R. Arelli ${ }^{5}$, Victor N. Niiti', Silvia Cianzio ${ }^{7}$, Stella K. Kantartzi ${ }^{2}$, and Khalid Meksem²
}

${ }^{1}$ Plant Genomics \& Biotechnology Lab, Department of Biological Sciences, Fayetteville State University, Fayetteville, NC, USA; ${ }^{2}$ Department of Plant, Soil, and Agricultural Systems, Southern Illinois University, Carbondale, IL, USA; ${ }^{3}$ Soybean Genomics and Improvement Lab, 10300 Baltimore Ave, Bldg. 006, Rm. 201, Beltsville, MD 20705; ${ }^{4}$ Unite de Recherche En Genomique Vegetale, INRA, Ivry, France; ${ }^{5}$ USDA-ARS Midsouth Area, Jackson, TN, USA; ${ }^{6}$ Department of Agriculture, Alcorn State University, Alcorn State, MS, USA; ${ }^{7}$ Plant Pathology Department and Agronomy Department, lowa State University, Ames, IA 50011-1010.

Received: February 24, 2014 / Accepted: April 4, 2014

\begin{abstract}
Soybean cyst nematode caused by Heterodera glycines Ichinohe is the most devastating pest in soybean [Glycine max (L.) Merr.]. Resistance to SCN is complex, polygenic, race and cultivar specific, and it is controlled by several quantitative trait loci (QTL). Our objective was to identify and map QTL for SCN resistance to races 3 (HG Type 0) and 5 (HG Type 2.5.7) using a high density SNP-based genetic linkage map based on the PI438489B by 'Hamilton' (PIxH, $n=50$ ) recombinant inbred line population. The PI438489B by Hamilton map contained 648 SNPs distributed on 31 LGs with coverage of 1,524.7 cM and an average distance of $2.35 \mathrm{cM}$ between two markers (Kassem et al., 2011). Using interval mapping (IM) and composite interval mapping (CIM), eight QTL were identified for SCN resistance to races 3 and 5 on 7 different soybean chromosomes. Four QTL for resistance to SCN race 3 were identified and mapped on chromosomes 7,13 , 15, and 16. Similarly, four QTL for resistance to SCN race 5 were identified and mapped on chromosomes 5, 8, and 11. The QTL identified here will be highly beneficial in breeding programs to develop cultivars with resistance to both SCN races 3 and 5 .

Keywords: Soybean, SCN, Race 3, Race 5, QTL, RIL, PI438489B, 'Hamilton'.
\end{abstract}

\section{Introduction}

Soybean [Glycine max (L.) Merr.] cyst nematode (SCN) caused by Heterodera glycines Ichinohe is the most devastating diseases causing high yield losses worldwide (Wrather et al., 2001, 2006). Plants infected with cyst nematodes (H. glycines) show symptoms of leaf chlorosis, root necrosis, reduced root growth, and severe seed weight reduction (Wrather et al., 2001, 2006). The average crop losses related to $\mathrm{SCN}$ in US can range from $5-80 \%$ depending on rainfall, soil fertility, and presence of other diseases such as sudden death syndrome (SDS), slerotinia stem rot, and other nematodes such as Meloidogyne incognita and Pratylenchus spp. (Wrather et al., 1995; Palmateer et al., 2000).

Chemical control was used to limit the populations of nematodes in fields; however, because of the toxicity of these chemicals, this practice was drastically reduced recently (RodriguezKabana, 1992; Chitwood, 2002). Other common agronomic practices such as non-host crop rotation, the use of cover crops, delayed planting, sampling procedures, use of minimum tillage, maintaining proper soil fertility and $\mathrm{pH}$, and managing other soybean diseases and pests have also been used to limit SCN infection; however, varietal resistance is the most effective and economical measure against yield losses caused by SCN infestation (Haetherly et al., 1999; Abawi et al., 2000; Concibido et al., 2004; Chen et al., 2006; Miller et al., 2006). In general, SCN resistant cultivars are low yielding compared to the high yielding susceptible cultivars which makes it difficult to breed high yielding cultivars combined with resistance to SCN (Kopisch-

* Corresponding author: meksemk@siu.edu

PTLRSS
This is an Open Access article distributed under the terms of the Creative Commons Attribution License (http://creativecommons.org/licenses/by/3.0/), which permits unrestricted use, distribution, and reproduction in any medium, provided the original work is properly cited. 
Obuch et al., 2005; Gellin et al., 2006; Karangula et al., 2009). There are several races of nematodes which make resistance to SCN complex, race-cultivar specific (Diers et al., 1997; Yue et al., 2001 a,b; Niblack et al., 2002, 2003), and polygenic (Concibido et al., 2004). Therefore, QTL for SCN resistance were identified and mapped on the soybean genome using different populations (Concibido et al., 2004; Glover et al., 2004; Kabelka et al., 2005; Guo et al., 2006a,b; Kassem et al., 2006, 2007; Wu et al., 2009; Kazi et al., 2010).

For example, resistance to SCN race 3 (HG Type 0) was reported as bigenic in the 'Essex' by 'Forrest' (ExF) recombinant inbred line (RIL) population (Lightfoot et al., 2005) conditioned by rhg 4 on chromosomes 8 (LG A2) and 18 (LG G) (Meksem et al., 2001; Lightfoot et al., 2005; Kassem et al., 2006). However, a third minor QTL was identified and mapped on chromosome 2 (LG DIb) using the same ExF RIL population (Kassem et al., 2007). A recent study summarized all QTL for SCN resistance for more than a decade, from 1992 to 2003 (Concibido et al., 2004). This study identified QTL for SCN resistance to races 1, 2, $3,5,6$, and 14 on all chromosomes except chromosomes 2 (LG D1b), 9 (LG K), and 10 (LG O). However, a QTL for SCN resistance was recently identified on chromosome 2 (LG D l b, Kassem et al., 2007). To our knowledge, QTL for SCN resistance to races $4,7-13,15$, and 16 have not been reported yet.

The 'PI438489B' by 'Hamilton' RIL population used in this study was developed specifically to identify and map QTL for SCN resistance (Yue et al., 2001 a). Using this population, nine QTL for SCN resistance to races 1, 2, 3, 5, and 14 were identified on chromosomes 1 (LG D1 a), 4 (LG C1), 5 (LG A 1), 6 (LG C2), 8 (LG A2), 11 (LG B1), 14 (LG B2), 15 (LG E), and 18 (LG G) (Yue et al., 2001 a). Using F4-derived lines of a cross between cultivars 'Bell' and 'Colfax', QTL for SCN resistance to races 3 and 14 were identified on chromosomes 16 (LG J) and 18 (LG G) (Glover et al., 2004). Using F2-derived lines of a cross between 'PI 468916' by Glycine soja, two QTL for SCN resistance to race 3 were identified on chromosomes 15 (LG E) and 18 (LG G) (Kabelka et al., 2005).

Association between QTL underlying both SCN and SDS resistance has been reported in several genetic backgrounds (Prabhu et al., 1999; Meksem et al., 1999). For example, in the ExF RIL population, a cluster of 4 QTL underlying SDS resistance were identified and mapped on chromosome 18 (LG G; lqbal et al., 2001). One of these regions coincides with Rhgl that underlies resistance to SCN (lqbal et al., 2001; Concibido et al., 2004). Another region on chromosome 17 (LG D2) was reported to underlie resistance to both SDS and SCN (Concibido et al., 2004; De Farias et al., 2007; Wu et al., 2009). These regions are of interest to include in breeding programs to develop soybean cultivars with dual resistance to both SDS and $\mathrm{SCN}$ resistance.

The objective of this study was to map QTL for SCN resistance to races 3 and 5 using the 'PI438489B' by 'Hamilton' (PIxH, $n=50$ ) recombinant inbred line population and the recently published high density SNP-based genetic linkage map (Kassem et al., 2012).

\section{Materials and Methods}

\section{Plant Material}

The PI 438489B by 'Hamilton' recombinant inbred line (RIL) population $(\mathrm{PIxH}, \mathrm{n}=50)$ used in this study was developed at the University of Missouri Agronomy Research Center and has been described earlier (Yue et al., 2001a). The population was advanced to the F6:13 generation by Dr. Silvia Cianzio at the ISU research site at the Isabela Substation, Univ. of Puerto Rico, Isabela, Puerto Rico.

\section{DNA Isolation}

DNA isolation was performed as described earlier (Kassem et al., 2012). Briefly, DNeasy 96 Tissue Kit (QIAGEN, Inc., Valencia, CA, USA) was used to extract DNA from young leaves of 15 days-old seedlings grown in the greenhouse. DNA samples were then quantified and diluted to a final concentration of 100 $\mathrm{ng} / \mu \mathrm{l}$.

\section{SNP Genotyping}

SNP genotyping was performed using the GoldenGate assay as described previously (Hyten et al., 2008).

\section{SCN Phenotypic Scoring}

The source and the method for developing a near -homogeneous populations of SCN Race 3 (HG Type 0) and Race 5 (HG Type 2.5.7) used in this research was already described (Qui et al., 1999). Each of the two populations was increased individually for multiple generations and was maintained separately on a susceptible cultivar Hutcheson in the greenhouse at USDA-ARS, Soybean Research Lab, Jackson, TN.

A bioassay using revised classification system as described by Niblack et al., (2002) was used to evaluate the RIL population for the soybean cross. The revised classification system includes seven indicator lines and a susceptible line for determination of soybean reaction to SCN. The indicator lines include PI 548402 (Peking), PI 88788, PI 90763, PI437654, PI 209332, PI 89772, PI 548316 (Cloud) and a standard susceptible cultivar, respectively.

Method for the SCN bioassay performed in the greenhouse followed established protocols (Arelli et al., 2000) with the modifications described in Arelli and Wang, (2008). Each plant was grown in $7-\mathrm{cm}$ in diameter clay pot filled with steam sterilized soil on a greenhouse bench top with an evaporative cooling and under bench heating system. A computerized system has regulated duration of light, heating and cooling systems in the greenhouse during the bioassay for proper growth of soybean seedlings and nematodes. Ten seedlings for each of the RIL, indicator lines a susceptible control and both the parents were included in the experiment and maintained at $27 \pm 2{ }^{\circ} \mathrm{C}$. The seedlings were grown for 3 to 4 days prior to their inoculation with SCN Race 5 (HG Type 2.5.7) eggs and juveniles. Each seedling was inoculated with $5 \mathrm{ml}$ of inoculum consisting approximately 2,000 eggs and juveniles. The eggs and juveniles were suspended in deionized distilled water and a Pippettor dispensed the inoculums closer to the roots of the seedlings.

Approximately 30 days after the inoculation, plant roots were individually washed with a stron jet of water to dislodge the females and cysts. These were counted under a stereomicroscope, and a female index ( $F I \%$ ) was calculated for the number of females developing on each soybean plant (Golden et al., 1970). Female index is the number of SCN females occurring on a given soybean plant expressed as the percentage of mean number of females on a standard susceptible used in the bioas- 
say.

Ratings of resistant ( $\mathrm{FI}=0$ to $9 \%$ ) and susceptible ( $\mathrm{FI}=60 \%$ and more) used to classify the reaction of soybean plants (RILs) were based on Schmitt and Shannon (1992).

\section{Statistical Data Analysis}

A one-way ANOVA based on replicated data was conducted to estimate the differences between RI lines and parents. Descriptive statistics were calculated for the RI lines and their parents from raw data. Normality of distribution was tested by Shapiro-Wilk W test for indexes of parasitism. All analyses were performed on JMP 8.02 (SAS Institute Inc., Cary, NC, USA).

\section{Traits QTL Mapping}

We mapped resistance to $S C N$ race 3 and 5 using both IM and CIM methods of WinQTL Cartographer (Wang et al., 2005) as described earlier (Kassem et al., 2012). Briefly, we used the Model 6 and default settings. Linkage was determined by 300 permutations and QTL presence was reported at $P \leq 0.05$ and LOD scores $\geq 2.5$.

\section{Genetic Map Construction}

The 'PI438489B' by 'Hamilton' SNP-based genetic linkage map has been described earlier (Kassem et al., 2012). Briefly, the genetic map was composed of 648 SNPs distributed on 31 LGs with coverage of $1,524.7 \mathrm{cM}$ and an average distance of $2.35 \mathrm{cM}$ between two markers (Kassem et al., 2012). The genetic map was constructed using JoinMap 4 (Van Ooijen, 2006). Chromosomes and QTL positions were drawn using MapChart 2.2 (Voorrips, 2002).

\section{Finding Genes that Underlie SCN QTL}

Genes that underlie SCN QTL identified in this study were found as described earlier (Kassem et al., 2012). Briefly, each QTL was bounded by two SNPs. The SNP sequences were obtained from the NCBI SNP Database (http://www.ncbi.nlm.nih. gov/projects/SNP/) and used in a BLAST search of the Glycine max Genome Sequence (http://soybase.org/gbrowse/cgi-bin/ gbrowse/gmax1.01/) and gene names and sequences were identified (Kassem et al., 2012).

\section{Results}

\section{SNP-Based Genetic Map}

The 'PI438489B' by 'Hamilton' SNP-based genetic linkage map has been described earlier (Kassem et al., 2012). Briefly, the genetic map was composed of 648 SNPs distributed on 31 LGs with coverage of $1,524.7 \mathrm{cM}$ and an average distance of $2.35 \mathrm{cM}$ between two markers (Kassem et al., 2012).

\section{Distribution and Variation for Index of Parasitism}

Segregation data for SCN Race 3 and 5 index of parasitism in the RIL population were tested with Shapiro-Wilk W test and were found that follow normal distribution (Figure 1). This result indicates that data can be used for QTL analysis and mapping. According to the data, $52 \%$ of the RILs showed an in-

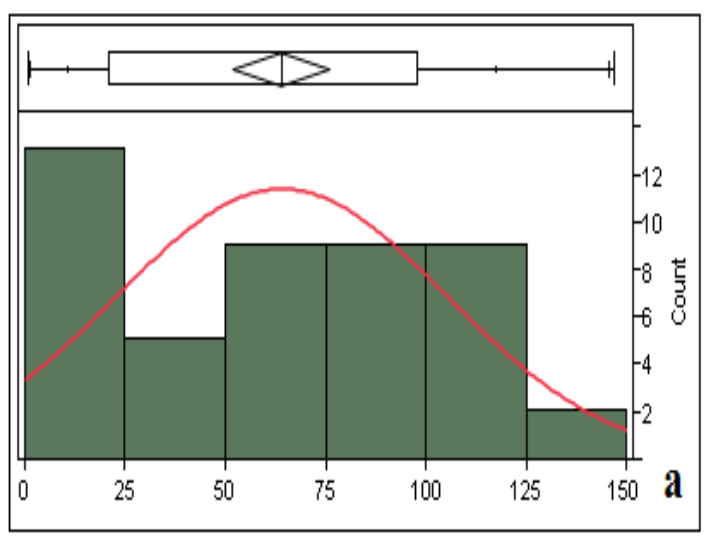

SCN Race 3 Index of Parasitism

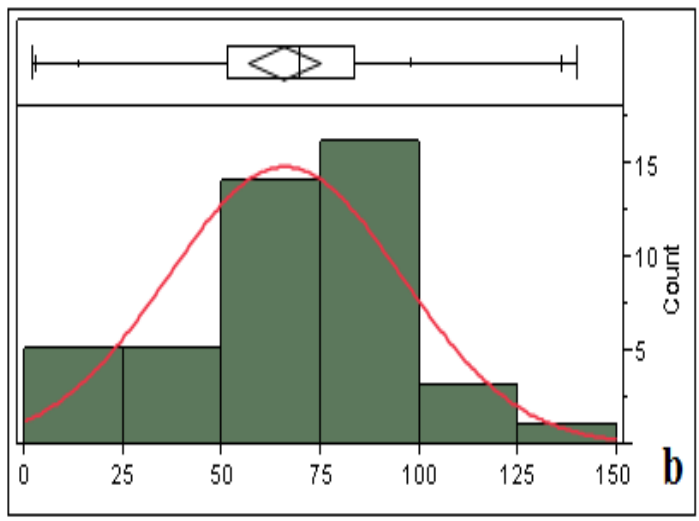

SCN Race 5 Index of Parasitism

Figure 1. Frequency distributions of SCN resistance traits: Index of Parasitism (IP) for SCN races 3 (a) and 5 (b) in the PI438489B by 'Hamilton' RIL population $(n=50)$.

dex of parasitism higher than 'Hamilton' and only one individual had an index lower than 'PI438489B'. The difference between $\mathrm{PI} 438489 \mathrm{~B}$ and 'Hamilton' and also between parental lines and $\mathrm{RI}$ were not significant at the $\mathrm{P}<0.05$ level.

\section{SCN Resistance QTL}

We used interval mapping (IM) and composite interval mapping (CIM) of WinQTL Cartographer (Wang et al., 2005) to identify and map QTL for SCN resistance to races 3 and 5 of the nematode (Table 1). Index of parasitism was used as a phenotypic parameter as described earlier (Arelli et al., 1992). Indexes of parasitism were estimated for SCN races 3 (IP SCN3) and 5 (IP SCN5) 33-34 DAP.

A total of 8 QTL that underlie SCN resistance were identified and mapped on 7 different chromosomes of the soybean genome. Six QTL were identified CIM and 2 in IM QTL analysis. The first QTL that underlie resistance to SCN3 (qSCN001-01) was identified by the marker interval ss $107925701-s s 107918678$ on chromosome 7 (LG M). The QTL spanned approximately $8 \mathrm{cM}$ and had a peak LOD score of 3.2 (Table 1, Figure 2). The second QTL that underlie resistance to SCN3 (qSCN001-02) was identified by the marker interval ss $107920816-s s 107912529$ on chromosome 13a (LG F). The QTL spanned only $0.6 \mathrm{cM}$ and 
Table 1. The eight QTL that underlie SCN resistance found in the soybean 'PI438489B' by 'Hamilton' RIL population. The traits measured were female index of parasitism (IP) after infection by $\mathrm{H}$. glycines races 3 and 5. QTL were named according to the Soybean Genetics Committee recommendations as revised in March 2007 (http://soybase. org/resources/QTL.php).

\begin{tabular}{|c|c|c|c|c|c|c|c|}
\hline Trait & No. & QTL & Chr./LG & Marker/Interval & Position (cM) & LOD & $\overline{\mathbf{R}^{2}}$ \\
\hline \multicolumn{8}{|l|}{ CIM } \\
\hline \multirow[t]{3}{*}{ IP SCN3 } & 1 & qSCNOO1-01 & $7 / M$ & ss $107925701-s s 107918678$ & $0-8$ & 3.2 & 22.4 \\
\hline & 2 & qSCNOO1-02 & $13 a / F$ & ss $107920816-s s 107912529$ & $3.6-4.2$ & 4.1 & 8.9 \\
\hline & 3 & qSCNOO1-03 & $15 \mathrm{~b} / \mathrm{E}$ & ss $107913532-s s 107930960$ & $0-13$ & 2.8 & 16.1 \\
\hline \multirow[t]{3}{*}{ IP SCN5 } & 4 & qSCNO02-01 & $5 \mathrm{~b} / \mathrm{A} 1$ & ss $107921684-s s 107919814$ & $10.4-14.6$ & 2.9 & 43.0 \\
\hline & 5 & qSCN002-02 & $8 / A 2$ & ss $107919498-s s 107930668$ & $0-8$ & 3.6 & 43.3 \\
\hline & 6 & qSCNO02-03 & $11 \mathrm{~b} / \mathrm{B} 1$ & ss $107920383-s s 107922154$ & $0-2.5$ & 2.6 & 38.9 \\
\hline \multicolumn{8}{|l|}{ IM } \\
\hline \multirow[t]{2}{*}{ IP SCN3 } & (1) & qSCNO01-01 & $7 / M$ & ss $107925701-s s 107918251$ & $0-18$ & 3.4 & 22.4 \\
\hline & 7 & qSCNOO1-04 & $16 / J$ & ss $107915281-s s 107913369$ & $4-21$ & 2.9 & 10.4 \\
\hline IP SCN5 & 8 & qSCN002-04 & $8 / A 2$ & ss $107930810-s s 107927037$ & $97-100$ & 3.7 & 27.8 \\
\hline
\end{tabular}

had a peak LOD score of 4.1 (Table 1, Figure 2). The third QTL that underlie resistance to SCN3 (qSCN001-03) was identified by the marker interval ss107913532-ss107930960 on chromosome 15b (LG E). The QTL spanned approximately $13 \mathrm{cM}$ and had a peak LOD score of 2.8 (Table 1, Figure 2). The first QTL that underlie resistance to SCN5 (qSCN002-01) was identified by the marker interval ss107921684-ss107919814 on chromosome 5b (LG A1). The QTL spanned approximately 4.2 CM and had a peak LOD score of 2.9 (Table 1, Figure 2). The second QTL that underlie resistance to SCN5 (qSCN002-02) was identified by the marker interval ss107919498-ss107930668 on chromosome 8 (LG A2). The QTL spanned approximately 8 $C M$ and had a peak LOD score of 3.6 (Table 1, Figure 2). The third QTL that underlie resistance to SCN5 (qSCN002-03) was identified by the marker interval ss107920383-ss107922154 on chromosome $11 \mathrm{~b}$ (LG B 1). The QTL spanned only $2.5 \mathrm{cM}$ and had a peak LOD score of 2.6 (Table 1, Figure 2).

Using IM, three QTL were identified for SCN resistances to races 3 and 5 (SCN3 \& SCN5); however, one QTL is the same QTL identified in CIM (qSCNO01-01, Table 1, Figure 2). The seventh QTL for resistance to SCN3 (qSCN001-04) was identified by the marker interval ss107915281-ss107913369 on chromosome 16 (LG J). The QTL spanned $17 \mathrm{cM}$ and had a peak LOD score of 2.9 (Table 1, Figure 2). The eight QTL for resistance to SCN5 (qSCN002-04) was identified by the marker interval ss107930810-ss107927037 on chromosome 8 (LG A2). The QTL spanned only $3 \mathrm{cM}$ and had a peak LOD score of 3.7 (Table 1, Figure 2).

\section{Analysis of Candidate Genes}

The genomic intervals containing QTL for SCN resistance ranged from 0.6 to $18 \mathrm{cM}$ (Table 1). The analysis of sequences of these regions revealed the presence of 26 genes 18 among which are for resistance to SCN race 5 and 8 are for resistance to $\mathrm{SCN}$ race 3 (Table 2). Those genes have been discovered earlier from Arabidopsis thaliana, Oryza sativa, Medicago truncatula, Prunus mume, and Vigna radiate (Table 2).

\section{Discussion}

The PI438489 and Hamilton genetic linkage map as described earlier contained 648 SNPs, 31 LGs, a map coverage of 1,524.7 cM, and an average distance of $2.35 \mathrm{cM}$ between markers (Kassem et al., 2012). The same map was used previously to locate QTL for SDS resistance (Kassem et al., 2012) and also in this study for mapping QTL for SCN resistance to races 3 and 5.

Using IM and CIM, eight QTL for SCN resistance to races 3 and 5 were identified and mapped on 7 different soybean chromosomes. Four QTL for resistance to SCN race 3 were identified and mapped on chromosomes 7, 13, 15, and 16. These QTL were qSCN001-01, qSCN001-02, qSCN001-03, and qSCN001-04, respectively. At the same position of the QTL qSCN001-01 identified on chromosome 7 (LG M), other studies mapped QTL for sucrose concentration (Maughan et al., 2000) and seed weight (Specht et al., 2001). Interestingly, this chromosome contains a cluster of 2 other QTL for SCN resistance to races $1,3,5$, and 14 from different genetic backgrounds including a patented region (Concibido et al., 2004). In the other hand, at the same position of qSCN001-02 found on chromosome 13a (LG F), a QTL for SCN resistance to races 1, 3, and 5 was found and mapped (Concibido et al., 2004). In addition, QTL for phosphorus leaf content (Li et al., 2005) and seed weight (Specht et al., 2001) were also identified and mapped in this region. On chromosome 15b (LG E) where qSCN001-03 was identified, two other QTL for SCN resistance to races 2, 3, and 14 (Yue et al., 2001 a,b; Concibido et al., 2004). One of the two QTL was identified in 'PI 438489B' one of the parents of the RIL population used in this study. Therefore, qSCN001-03 is a confirmed QTL and can be designated cqSCNO01-03. At this same position, QTL for corn earworm resistance (Terry et al., 2000), protein, and oil content (Diers et al., 1992) were also mapped. The fourth SCN resistance QTL (qSCN001-04) on chromosome 16 (LG J) map at the same region of the QTL for resistance to SCN race 3 identified previously in different genetic backgrounds (Concibido et al., 2004). This QTL has been confirmed and is called cqSCN001-04. In the same region, QTL for corn earworm resistance (Rector et al., 2000), maturity date (Orf et al., 1999), 
Table 2. Potential candidate genes found in the genomic regions containing QTL for SCN races 3 and 5.

\begin{tabular}{|c|c|c|}
\hline QTL and Gene Name & Gene Description & $\begin{array}{l}\text { Gene } \\
\text { Frequency }\end{array}$ \\
\hline $\begin{array}{l}\text { CIM_FI SCN5 qSCNO02-01 } \\
\text { TA54513_3847 }\end{array}$ & $\begin{array}{l}\text { Expressed protein [Oryza sativa (japonica cultivar- } \\
\text { group)] }\end{array}$ & 2 \\
\hline $\begin{array}{l}\text { CIM_FI SCN5 qSCNO02-03 } \\
\text { CA910878 }\end{array}$ & $\begin{array}{l}\text { Expressed protein [Oryza sativa (japonica cultivar- } \\
\text { group)] }\end{array}$ & 2 \\
\hline $\begin{array}{l}\text { CIM_FI SCN5 qSCNO02-02 } \\
\text { TA49604_3847 }\end{array}$ & $\begin{array}{l}\text { IMP dehydrogenase/GMP reductase [Medicago } \\
\text { truncatula (Barrel medic)] }\end{array}$ & 2 \\
\hline $\begin{array}{l}\text { CIM_FI SCN5 qSCNO02-03 } \\
\text { TA65691_3847 }\end{array}$ & $\begin{array}{l}\text { IMP dehydrogenase/GMP reductase [Medicago } \\
\text { truncatula (Barrel medic)] }\end{array}$ & 2 \\
\hline $\begin{array}{l}\text { CIM_FI SCN5 qSCNO02-02 } \\
\text { BE805951 }\end{array}$ & $\begin{array}{l}\text { Pathogenesis-related transcriptional factor and ERF } \\
\text { [Medicago truncatula (Barrel medic)] }\end{array}$ & 2 \\
\hline $\begin{array}{l}\text { CIM_FI SCN5 qSCNO02-03 } \\
\text { TA53626_3847 }\end{array}$ & $\begin{array}{l}\text { Pathogenesis-related transcriptional factor and ERF } \\
\text { [Medicago truncatula (Barrel medic)] }\end{array}$ & 2 \\
\hline $\begin{array}{l}\text { CIM_FI SCN5 qSCNO02-02 } \\
\mathrm{BI} 426783\end{array}$ & $\begin{array}{l}\text { Putative bHLH transcription factor [Arabidopsis thaliana } \\
\text { (Mouse-ear cress)] }\end{array}$ & 2 \\
\hline $\begin{array}{l}\text { CIM_FI SCN5 qSCNO02-03 } \\
\text { BE346647 }\end{array}$ & $\begin{array}{l}\text { Putative bHLH transcription factor [Arabidopsis thaliana } \\
\text { (Mouse-ear cress)] }\end{array}$ & 2 \\
\hline $\begin{array}{l}\text { CIM_FI SCN3 qSCNO01-01 } \\
\text { TA50770_3847 }\end{array}$ & $\begin{array}{l}\text { RNA-binding region RNP-1 [Medicago truncatula (Barrel } \\
\text { medic)] }\end{array}$ & 2 \\
\hline $\begin{array}{l}\text { CIM_FI SCN5 qSCNO02-03 } \\
\text { TA63841_3847 }\end{array}$ & $\begin{array}{l}\text { RNA-binding region RNP-1 [Medicago truncatula (Barrel } \\
\text { medic)] }\end{array}$ & 2 \\
\hline $\begin{array}{l}\text { CIM_FI SCN3 qSCNO01-03 } \\
\text { BG550778 }\end{array}$ & $\begin{array}{l}\text { Serine carboxypeptidase [Prunus mume (Japanese } \\
\text { flowering apricot)] }\end{array}$ & 2 \\
\hline $\begin{array}{l}\text { CIM_FI SCN5 qSCNO02-03 } \\
\text { TA63856_3847 }\end{array}$ & $\begin{array}{l}\text { Serine carboxypeptidase [Prunus mume (Japanese } \\
\text { flowering apricot)] }\end{array}$ & 2 \\
\hline $\begin{array}{l}\text { CIM_FI SCN3 qSCNO01-03 } \\
\text { DW247151 }\end{array}$ & Serine carboxypeptidase [Vigna radiata] & 2 \\
\hline $\begin{array}{l}\text { CIM_FI SCN5 qSCNO02-03 } \\
\text { BQ612344 }\end{array}$ & Serine carboxypeptidase [Vigna radiata] & 2 \\
\hline $\begin{array}{l}\text { CIM_FI SCN3 qSCNO01-03 } \\
\text { TA55260_3847 }\end{array}$ & unknown protein [Arabidopsis thaliana] & 2 \\
\hline $\begin{array}{l}\text { CIM_FI SCN5 qSCNO02-03 } \\
\text { CA783631 }\end{array}$ & unknown protein [Arabidopsis thaliana] & 2 \\
\hline $\begin{array}{l}\text { CIM_FI SCN3 qSCNO01-03 } \\
\text { AW568004 }\end{array}$ & $\begin{array}{l}\text { Expressed protein [Arabidopsis thaliana (Mouse-ear } \\
\text { cress)] }\end{array}$ & 3 \\
\hline $\begin{array}{l}\text { CIM_FI SCN5 qSCNO02-02 } \\
\text { AV780986 }\end{array}$ & $\begin{array}{l}\text { Expressed protein [Arabidopsis thaliana (Mouse-ear } \\
\text { cress)] }\end{array}$ & 3 \\
\hline $\begin{array}{l}\text { CIM_FI SCN5 qSCNO02-03 } \\
\text { AV407437 }\end{array}$ & $\begin{array}{l}\text { Expressed protein [Arabidopsis thaliana (Mouse-ear } \\
\text { cress)] }\end{array}$ & 3 \\
\hline $\begin{array}{l}\text { CIM_FI SCN3 qSCNO01-03 } \\
\text { TA57221_3847 }\end{array}$ & $\begin{array}{l}\text { Hypothetical protein [Medicago truncatula (Barrel } \\
\text { medic)] }\end{array}$ & 3 \\
\hline $\begin{array}{l}\text { CIM_FI SCN5 qSCNO02-02 } \\
\text { TA62904_3847 }\end{array}$ & $\begin{array}{l}\text { Hypothetical protein [Medicago truncatula (Barrel } \\
\text { medic)] }\end{array}$ & 3 \\
\hline $\begin{array}{l}\text { CIM_FI SCN5 qSCNO02-03 } \\
\mathrm{BI} 15865\end{array}$ & $\begin{array}{l}\text { Hypothetical protein [Medicago truncatula (Barrel } \\
\text { medic)] }\end{array}$ & 3 \\
\hline $\begin{array}{l}\text { CIM_FI SCN3 qSCNO01-01 } \\
\text { BM188802 }\end{array}$ & $\begin{array}{l}\text { Hypothetical protein [Arabidopsis thaliana (Mouse-ear } \\
\text { cress)] }\end{array}$ & 4 \\
\hline $\begin{array}{l}\text { CIM_FI SCN3 qSCNO01-03 } \\
\text { AV413006 }\end{array}$ & $\begin{array}{l}\text { Hypothetical protein [Arabidopsis thaliana (Mouse-ear } \\
\text { cress)] }\end{array}$ & 4 \\
\hline $\begin{array}{l}\text { CIM_FI SCN5 qSCNO02-02 } \\
\text { TA54574_3847 }\end{array}$ & $\begin{array}{l}\text { Hypothetical protein [Arabidopsis thaliana (Mouse-ear } \\
\text { cress)] }\end{array}$ & 4 \\
\hline $\begin{array}{l}\text { CIM_FI SCN5 qSCNO02-03 } \\
\text { BM887276 }\end{array}$ & $\begin{array}{l}\text { Hypothetical protein [Arabidopsis thaliana (Mouse-ear } \\
\text { cress)] }\end{array}$ & 4 \\
\hline
\end{tabular}


Chr_5b

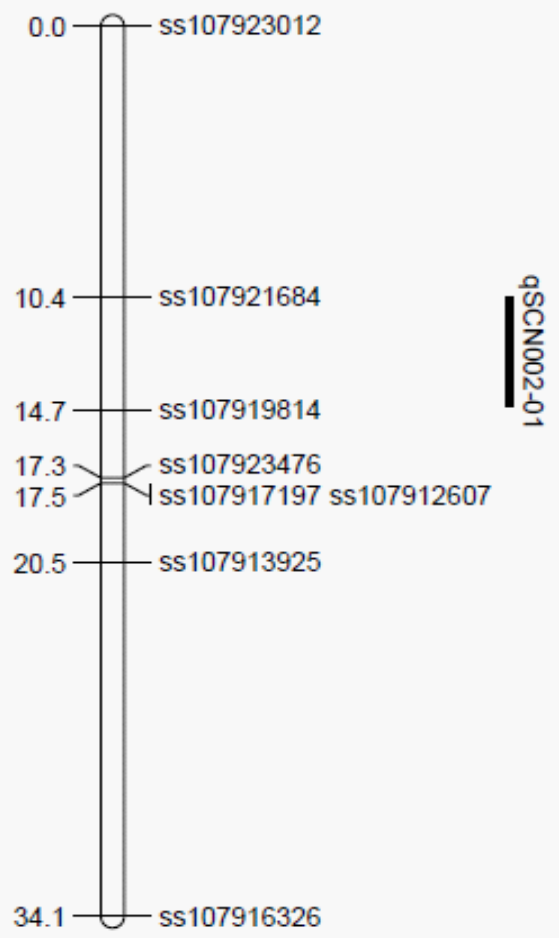

Chr_11b

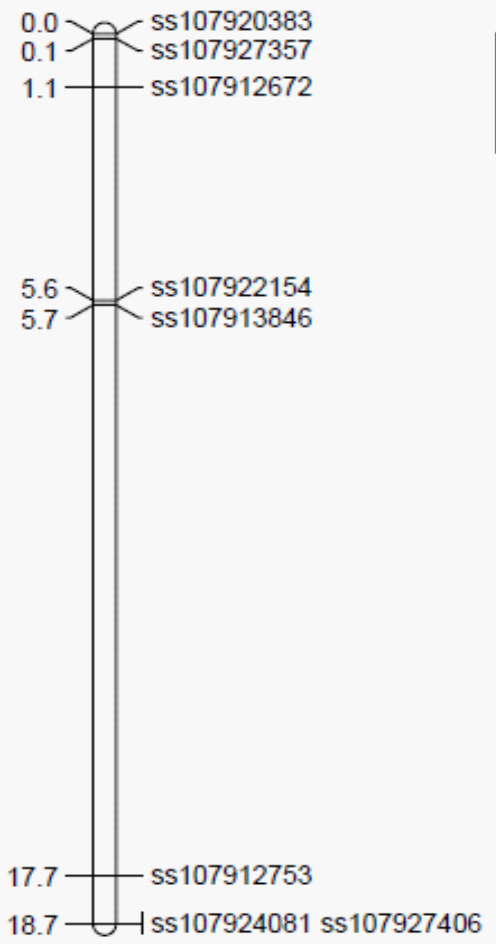

Chr_7

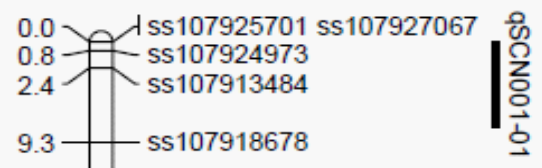

Chr_8

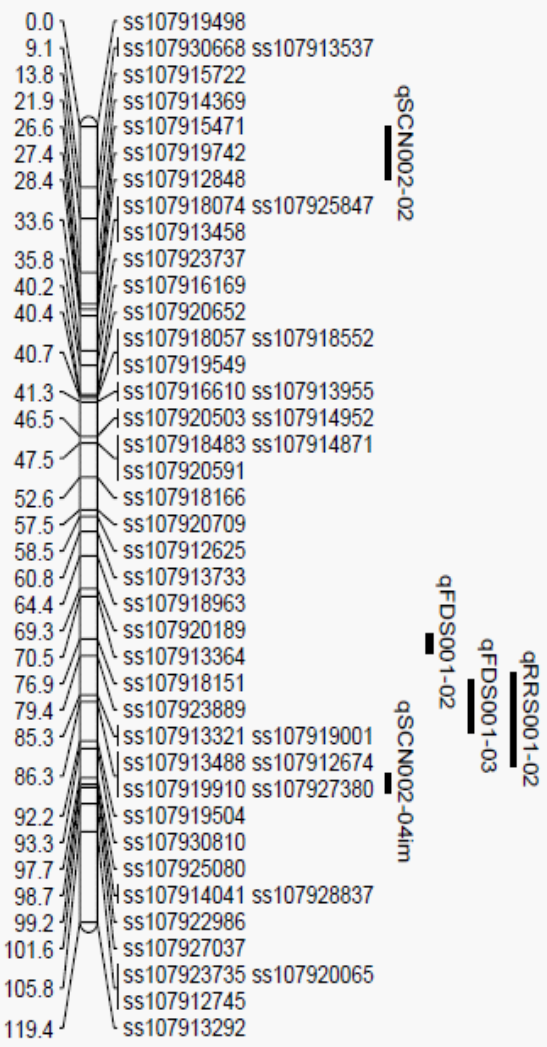

Chr_15b

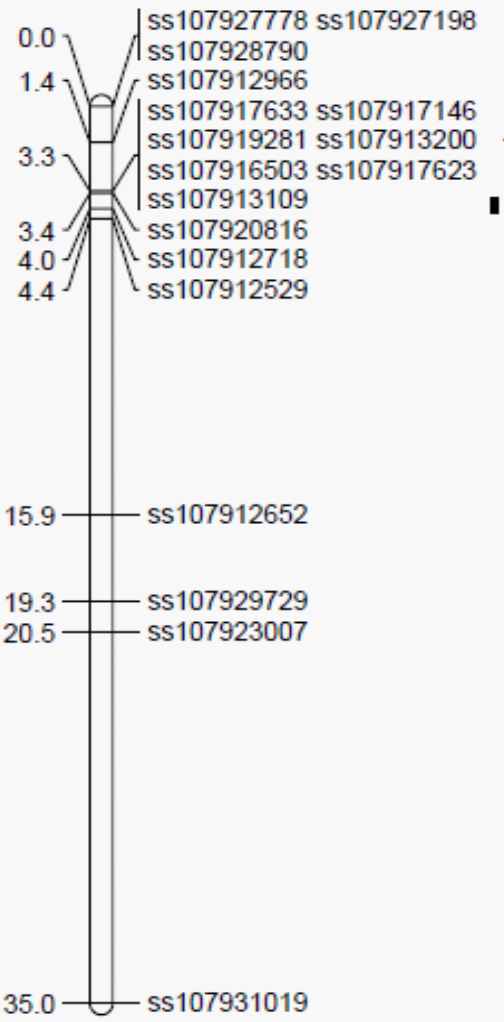

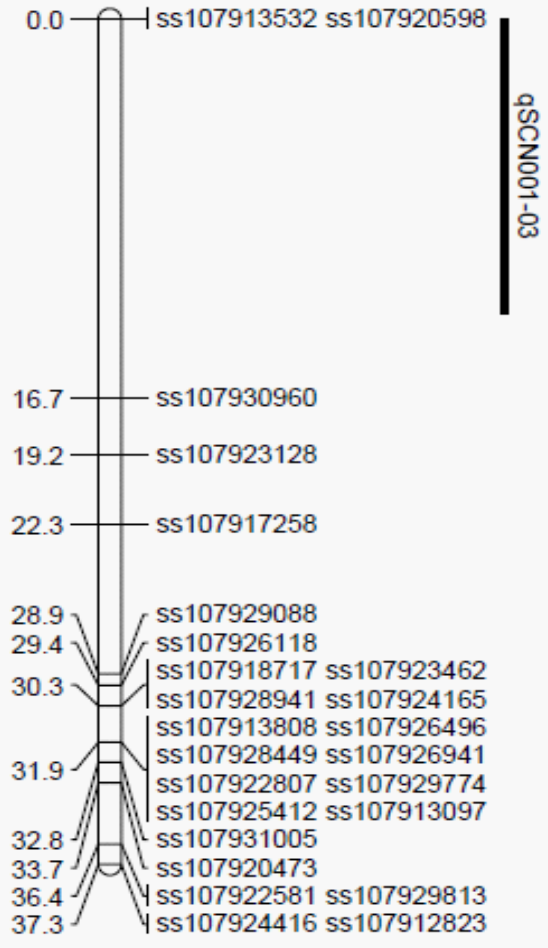

Figure 2. The positions of the eight QTL that confer resistance to SCN races 3 and 5 found in this PI438489B by 'Hamilton' RIL population ( $n=50$ ). 


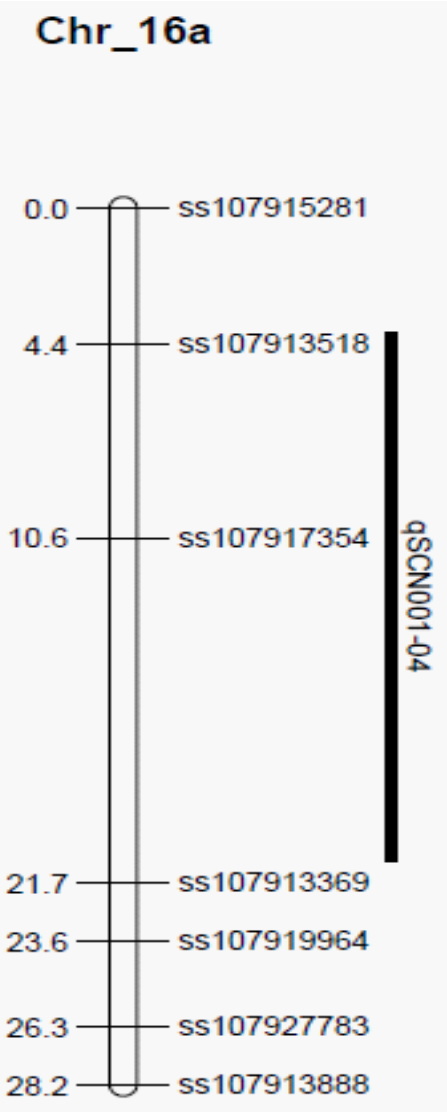

Figure 2. Coninued.

plant height (Mansur et al., 1996), and several other agronomic traits were identified (SoyBase, 2014).

Similarly, four QTL for resistance to $\mathrm{SCN}$ race 5 were identified and mapped on chromosomes 5, 8, and 11. These QTL were qSCNO02-01, qSCN002-02, qSCN002-03, and qSCNO02-04, respectively. Interestingly, two QTL for SCN resistance to races 2 and 3 were identified and mapped on chromosome 5b (LG A1) (Concibido et al., 2004). One of these QTL was mapped at the same position of qSCNOO2-01 identified in this study using the same RIL population (Yue et al., 2001a; Concibido et al., 2004). Therefore, this QTL can be designated as cqSCN002-01. Chromosome 8 (LG A2) is of interest because it contains Rhg 4 that was identified in 4 different genetic backgrounds (Concibido et al., 2004). Moreover, Rhg 4 was also mapped in 'Essex' by 'Forrest' RIL population (Meksem et al., 1999, 2001). The QTL for SCN resistance to race 5 identified on this chromosome (qSCN002-02), maps at the same region of Rhg4. This QTL was not identified previously in this population (Yue et al., 2001a) and is another confirmation of Rhg4 in a 6th genetic background. Interestingly, this chromosome contains also a cluster of QTL for sudden death syndrome (SDS) resistance. A total of five QTL were identified on this chromosome: two for SCN resistance and three for SDS resistance (Kassem et al., 2012) Three QTL for $\mathrm{SCN}$ resistance to races $1,2,3,5$, and 14 have been previously reported on chromosome $11 \mathrm{~b}$ (LG B 1) (Concibido et al., 2004) including one in this population (Yue et al., 2001 a). This QTL is confirmed here and can be designated cqSCN002-03. The fourth QTL for SCN resistance to race 5 (qSCN002-04), identified by IM, is the second QTL for SCN resistance identified on chromosome 8 (LG A2) and is very close to the cluster of SDS resistance QTL previously reported in this population (Kassem et al., 2012). This QTL overlaps with a QTL for resistance to SDS root rot resistance (qRRS001-02, Figure 2) previously reported in this same population (Kassem et al., 2012).

Several recent studies confirmed previously reported QTL or identified new ones for SCN resistance to several nematode races. For example, a QTL on chromosome 16 (LG J) was confirmed using near isogenic lines (NILs) along with Rhgl (Glover et al., 2004). Two new SCN resistance QTL were identified on chromosome 18 (LG G) and chromosome 15 (LG E) (Kabelka et al., 2005). These QTL confer resistance to race 3, were identified using a cross between G. soja and 'PI 468916', and were different from the SCN-resistance QTL previously reported on these two chromosomes (Kabelka et al., 2005). Interestingly, the SCN-resistance QTL on chromosome 15 (LG E) is at the same position of qSCN001-03 identified in this study. Therefore, this QTL is also confirmed and can be identified as cqSCN001-03. Another study identified QTL for SCN resistance to (1) race 5 on chromosome 3 (LG N), (2) race 1 (Rhg4) on chromosome 8 (LG A2), (3) races 2 and 5 on chromosome 11 (LG B 1), and (4) races 1, 2, and 5 (Rhg 1 ) on chromosome 18 (LG G) (Guo et al., 2006a). The SCN resistance QTL identified on chromosome 11 (LG B 1) (Guo et al., 2006a) is <10 cM from the QTL reported in this study. Moreover, the same QTL was recently reported in the same position (Wu et al., 2009). This QTL confirmed by two independent studies; therefore, this QTL may be designated cqSCN002-03. A recent study confirmed SCN resistance QTL on chromosomes 8 (LG A2), 11 (LG B 1), 15 (LG E), 16 (LG J), and 18 (LG G) using a meta-analysis of their locations (Guo et al., 2006b). In this study, we reported QTL for SCN resistance in all these chromosomes except chromosome 18 (LG G). Another recent study identified and refined the major SCN-resistance QTL on chromosomes 8 (LG A2), 11 (LG B 1), and 18 (LG G; Wu et al., 2009). The study identified other minor SCN-resistance QTL in all chromosomes of soybean except on chromosomes 2 (LG D1b) and 14 (LG B2) (Wu et al., 2009). However, a minor SCNresistance QTL was identified previously on chromosome 2 (LG DIb) (Kassem et al., 2007). Therefore, QTL for SCN resistance were identified and mapped in all soybean chromosomes (Concibido et al., 2004; Glover et al., 2004; Kabelka et al., 2005; Guo et al., 2006a,b; Kassem et al., 2007; Wu et al., 2008; Kazi et al., 2010). Two of the recent studies (Guo et al., 2006a; Wu et al., 2009) confirmed the SCN-resistance QTL identified and reported in this study (cqSCNO02-03). Another recent study confirmed Rhgl (LG G), Rhg4 (LG A2), and identified a new SCN resistance QTL on chromosome 17 (LG D2) using the 'Flyer' by 'Hartwig' RIL population (Kazi et al., 2010). The QTL on LG D2 was also identified in several other genetic backgrounds (Concibido et al., 2004) and is confirmed (cqSCN-005; Kazi et al., 2010).

GO annotation identified many genes in the QTL regions containing QTL for resistance to SCN races 3 and 5; however, these genes are reduced to 26 genes which play similar roles in plants. Among these genes are several expressed proteins in rice (Hossain et al., 2010); IMP dehydrogenase / GMP reductase, a pathogenesis-related transcriptional factor and ERF, and RNA-binding region RNP-1 in Medicago truncatula (Joseph ef al., unpublished; Town, 2005); a putative bHLH transcriptional factor, expressed protein, and unknown protein in Arabidopsis thaliana (Heim et al., 2003; Lin et al., 2000). 


\section{Conclusions}

The PI438489 and Hamilton genetic linkage map contained 648 SNPs, 31 LGs, a map coverage of 1,524.7 cM, and an average distance of $2.35 \mathrm{cM}$ between markers (Kassem et al., 2012). This map was used to map QTL for SDS resistance (Kassem et al., 2012) and SCN resistance to races 3 and 5 in this study.

A total of 8 QTL that underlie SCN resistance were identified and mapped on 7 different chromosomes of the soybean genome. The relationship between the nematode and the host is complex and poorly understood; however, the recently developed SCN genetic linkage map will be of great use to identify candidate genes involved in virulence and parasitism (Atibalentja et al., 2005). Moreover, the QTL identified here may be introduced in breeding programs to develop cultivars with dual resistance to SDS and SCN.

GO annotation identified 26 important genes in these genomic regions containing QTL for resistance to SCN races 3 and 5 . These could be potential candidate genes that need to be studied further to understand their role in SCN resistance in soybean.

\section{List of Abbreviations}

SCN: Soybean cyst nematode; SDS: Sudden death syndrome; DAP: Days after planting; RIL: Recombinant inbred line.

Authors Contributions

KMA: Performed QTL data analysis and drafted the manuscript.

LR: Performed SCN bioassays.

$\mathrm{DH}$ : Constructed the genetic linkage map.

SKK: Performed statistical data analysis.

$\mathrm{JB}$ : Contributed to editing the manuscript.

$A B$ : Contributed to editing the manuscript and the general concept of the study.

PRA: Developed the mapping population and helped in SCN bioassays.

SC: Developed the mapping population and helped in SCN bioassays.

KM: Provided the general concept of the study and helped in editing the manuscript.

*All authors contributed to editing the manuscript to this final version.

\section{Acknowledgments}

The authors would like to thank the United Soybean Board, Illinois Soybean Association, lowa Soybean Association, North Central Soybean Research Program, and the following individuals for their dedication and contributions to this work: Nieves Rivera, Manuel Mendez, Peter Lundeen and Kyle Vander Molen, lowa State University; Karen Williams for assistance with the GoldenGate assay. Dana Pekarchick, USDA-ARS, Soybean Research Lab., Jackson, TN.

\section{References}

Abawi GS, TL Widmer, and MR Zeiss (2000) Impact of soil health management practices on soilborne pathogens, nematodes and root diseases of vegetable crops. Appl Soil Ecol 15: 37-47.
Arahana VS, GL Graef, JE Specht, JR Steadman, and KM Eskridge (2001) dentification of QTLs for Resistance to Sclerotinia sclerotiorum in Soybean. Crop Sci 41: 180-188.

Arelli PR and D Wang (2008) Inheritance of cyst nematode resistance in a new genetic source, Glycine max PI 494182. J Crop Sci Biotech 11: 83-90.

Arelli PR, DA Sleper, P Yue, and JA Wilcox (200) Soybean reaction to Races 1 and 2 of Heterodera glycines. Crop Sci 40: 824-826.

Arelli PR, JA Wrather, and SC Anand (1992) Genetic diversity among isolates of Heterodera glycines and sources of resistance in soybeans. Plant Dis 76: 894-896.

Atibalentia A, S Bekal, LL Domier, TL Niblack, GR Noel, and KN Lambert (2005) A genetic linkage map of the soybean cyst nematode Heterodera glycines. Mol Gen Genomics 273: 273-281.

Chen S, DL Wyse, GA Johnson, PM Porter, SR Stetina, DR Miller, KJ Betts, LD Klossner, and MJ Haar (2006) Effect of cover crops alfalfa, red clover, and perennial ryegrass on soybean cyst nematode population and soybean and corn yields in Minnesota. Crop Sci 46: 1890-1897.

Chitwood DJ (2002) Phytochemical based strategies for nematode control. Ann Rev Phytopathol 40: 221-249.

Concibido VC, BW Diers, and PR Arelli (2004) A decade of QTL mapping for cyst nematode resistance in soybean. Crop Sci 44: 11211131.

De Farias ALN, R Hashmi, M Schmidt, SR Carlson, GL Hartman, S Li, RL Nelson, and BW Diers (2007) Mapping and confirmation of a new sudden death syndrome resistance QTL on linkage group D2 from the soybean genotypes PI 567374 and 'Ripley'. Mol Breeding 20: 53-62.

Diers BW, P Keim, WR Fehr, and RC Shoemaker (1992) RFLP analysis of soybean seed protein and oil content. Theor Appl Genet 83: 608-612.

Diers BW, HT Skorupska, PR Arelli, and SR Cianzio (1997) Genetic Relationships among Soybean Plant Introductions with Resistance to Soybean Cyst Nematodes. Crop Sci 37: 1966-1972.

Gellin JR, PR Arelli, and GA Rojas-Cifuentes (2006) Using independent culling to screen plant introductions for combined resistance to soybean cyst nematode and sudden death syndrome. Crop Sci 46: 2081-2083.

Glover KD, D Wang, PR Arelli, SR Carlson, SR Cianzio, and BW Diers (2004) Near isogenic lines confirm a soybean cyst nematode resistance gene from PI 88788 on linkage group J. Crop Sci 44: 936-941.

Golden AM, JM Epps, RD Riggs, LA Duclos, JA Fox, and RL Bernard (1970) Terminology and identity of infraspecific forms of the soybean cyst nematode, (Heterodera glycines). Plant Dis 54: 544-546.

Guo B, DA Sleper, PR Arelli, JG Shannon, and HT Nguyen (2005) Identification of QTLs associated with resistance to soybean cyst nematode races 2, 3 and 5 in soybean PI 90763. Theor Appl Genet 111 : 965-971.

Guo B, DA Sleper, P Lu, JG Shannon, HT Nguyen, and PR Arelli (2006b) QTL associated with resistance to soybean cyst nematode in soybean: Meta-analysis of QTL locations. Crop Sci 46: 595-602.

Guo B, DA Sleper, HT Nguyen, PR Arelli, and JG Shannon (2006a) Quantitative trait loci underlying resistance to three soybean cyst nematode populations in soybean PI 404198A. Crop Sci 46: 224233.

Heatherly LG, A Blaine, HF Hodges, RA Wesley, and N Buehring (1999) Variety selection, planting date, row spacing, and seeding rate. In Soybean production in the midsouth. Edited by Heatherly LG, Hodges RA. Florida: CRC Press; 42-51.

Heim MA, M Jakoby, M Werber, C Martin, B Weisshaar, and PC Bai- 
ley (2003) The basic helix-loop-helix transcription factor family in plants: a genome-wide study of protein structure and functional diversity. Mol Biol Evol 20 (5): 735-747.

Hossain MA, JI Cho, M Han, CH Ahn, JS Jeon, G An, and PB Park (2010) The ABRE-binding bZIP transcription factor OsABF2 is a positive regulator of abiotic stress and $A B A$ signaling in rice. J Plant Physiol 167 (17): 1512-1520.

Iqbal MJ, K Meksem, VN Nijii, MA Kassem, and DA Lightfoot (2001) Microsatellite markers identify three additional quantitative trait loci for resistance to soybean sudden-death syndrome (SDS) in Essex by Forrest RILs. Theor Appl Genet 102: 187-192.

Joseph B, JA Schlueter, J Du, MA Graham, J Ma, and RC Shoemaker (unpublished) Retrotransposons within the syntenic regions between soybean and Medicago truncatula and their contribution to local genome evolution. NCBI Database [Accession: ACU01864.1; GI: 255317087].

Kabelka EA, SR Carlson, and BW Diers (2005) Localization of tow loci that confer resistance to soybean cyst nematode from Glycine soja PI 468916. Crop Sci 45: 2473-2481.

Karangula UB, MA Kassem, L Gupta, HA El-Shemy, and DA Lightfoot (2009) Locus interactions underlie seed yield in soybeans resistant to Heterodera glycines. Curr Issues Mol Biol 11 (Suppl.): i73-84.

Kassem MA, K Meksem, AJ Wood, and DA Lightfoot (2007) Loci underlying SDS and SCN resistance mapped in the 'Essex' by 'Forrest' soybean recombinant inbred lines. Rev Biol Biotech 6: 2-10.

Kassem MA, L Ramos, L Leandro, DL Hyten, S Kantartzi, RL Grier, RS Cianzio, and K Meksem (2012) The 'PI 438489B' by 'Hamilton' SNPBased Genetic Linkage Map of Soybean [Glycine max (L.) Merr.] Identified Quantitative Trait Loci that Underlie Seedling SDS Resistance. Plant Genetics, Genomics, and Biotechnology 1 (1): 18-30.

Kassem MA, J Shultz, K Meksem, Y Cho, AJ Wood, MJ lqbal, and DA Lightfoot (2006) An Updated 'Essex' by 'Forrest' Linkage Map and First Composite Map of QTL Underlying Six Soybean Traits. Theor Appl Genet 113(6): 1015-1026.

Kazi S, J Shultz, J Afzal, R Hashmi, M Jasim, J Bond, PR Arelli, and DA Lightfoot (2010) Iso-lines and inbred-lines confirmed loci that underlie resistance from cultivar 'Hartwig' to three soybean cyst nematode populations. Theor Appl Genet 120 (3): 633-644.

Kopisch-Obuch FJ, RL McBroom, and BW Diers (2005) Association between soybean cyst nematode resistance loci and yield in soybean. Crop Sci 45: 956-965.

Li YD, YJ Wang, YP Tong, JG Gao, JS Zhang, and SY Chen (2005) QTL mapping of phosphorus deficiency tolerance in soybean (Glycine max L. Merr.). Euphytica 142: 137-142.

Lightfoot DA, VN Niiti, PT Gibson, MA Kassem, MJ lqbal, K Meksem (2005) Registration of the Essex by Forrest Recombinant Inbred Line (RIL) Mapping Population. Crop Sci 45 (4): 1678-1781.

Lin X, S Kaul, TP Shea, CY Fujii, M Shen, SE VanAken, ME Barnstead, TM Mason, CL Bowman, CM Ronning, MI Benito, AJ Carrera, TH Creasy, CR Buell, CD Town, WC Nierman, CM Fraser, and JC Venter. Expressed protein [Arabidopsis thaliana]. NCBI Database. [Accession: AAD20688; GI: 4432839].

Mansur LM, JH Orf, K Chase, T Jarvik, PB Cregan, and KG Lark (1996) Genetic mapping of agronomic traits using recombinant inbred lines of soybean. Crop Sci 36 (5): 1327-1336.

Maughan PJ, MA Saghai Maroof, and GR Buss (2000) Identification of quantitative trait loci controlling sucrose content in soybean (Glycine max). Mol Breeding 6 (1): 105-111.

Meksem K, TW Doubler, K Chancharoenchai, VN Njiti, SJC Chang, PR Arelli, PB Cregan, LE Gray, PT Gibson, and DA Lightfoot (1999) Clustering among loci underlying soybean resistance to Fusarium solani, SDS and SCN in near-isogenic lines. Theor Appl Genet 99:
$1131-1142$.

Meksem K, P Pangiotis, D Hyten, V Njiti, DA Lightfoot, and PR Arelli (2001) Forrest resistance to soybean cyst nematode is bi-genic: saturation mapping of the rhgl and Rhg 4 loci. Theor Appl Genet 103: 710-717.

Miller DR, SY Chen, PM Porter, GA Johnson, DL Wyse, SR Stetina, LD Klossner, and GA Nelson (2006) Evaluation of rotation crops for management of the soybean cyst nematode in Minnesota. Agron J 98: 569-578.

Niblack TL, PR Arelli, GR Noel, GH Opperman, JH Orf, DP Schmitt, JG Shannon, and GL Tylka (2002) A Revised Classification Scheme for Genetically Diverse Populations of Heterodera glycines. J Nematol 34 (4): 279-288.

Niblack TL, GR Noel, and KL Lambert (2003) The Illinois SCN type test: practical application of the HG Type classification system. J Nematol 35: 345-355.

Orf JH, K Chase, T Jarvik, LM Mansur, PB Cregan, FR Adler, and KG Lark (1999) Genetics of soybean agronomic traits: I. Comparison of three related recombinant inbred populations. Crop Sci 39 (6): 1642-1651.

Palmateer AJ, ME Schmidt, SR Stetina, and JS Russin (2000) Temperature effects on race determination in Heterodera glycines. J Nematol 32: 349-355.

Prabhu RR, VN Njiti, BB Johnson, JE Johnson, ME Schmidt, JH Klein, and DA Lightfoot (1999) Selecting soybean cultivars for dual resistance to soybean cyst nematode and sudden death syndrome using two DNA markers. Crop Sci 39: 982-987.

Rector BG, JN All, WA Parrott, and HR Boerma (2000) Quantitative trait loci for antibiosis resistance to corn earworm in soybean. Crop Sci 40 (1): 233-238.

Rodriguez-Kabana R (1992) Chemical control. In Biology and Management of soybean cyst nematode. Edited by Riggs RD, Wrather JA. St. Paul: APS Press; 1992.

Ruben E, A Jamai, J Afzal, VN Niiti, K Triwitayakorn, MJ Iqbal, S Yaegashi, R Bashir, S Kazi, PR Arelli, CD Town, H Ishihara, K Meksem, and DA Lightfoot (2006) Genomic analysis of the rhg 1 locus: candidate genes that underlie soybean resistance to the cyst nematode. Mol Gen Genomics 276: 503-516.

Schmitt DP and JG Shannon (1992) Differentiating soybean responses to Heterodera glycines races. Crop Sci 32: 275-277.

SoyBase (2014) [http://soybase.agron.iastate.edu]. Accessed March 2014.

Specht JE, K Chase, M Macrander, GL Graef, J Chung, JP Markwell, M Germann, JH Orf, and KG Lark (2001) Soybean Response to Water: A QTL Analysis of Drought Tolerance. Crop Sci 41: 493-509.

Stombaugh SK, JH Orf, HG Jung, K Chase, KG Lark, and DA Somers (2004) Quantitative Trait Loci Associated with Cell Wall Polysaccharides in Soybean Seed. Crop Sci 44: 2101-2106.

Terry LI, K Chase, T Jarvik, JH Orf, L Mansur, and KG Lark (2000) Soybean quantitative trait loci for resistance to insects. Crop Sci 40 (2): 375-382.

Town CD (2005) Pathogenesis-related transcriptional factor and ERF [Medicago truncatula]. NCBI Database [Accession: ABN08981; GI:1 24361009$]$.

Van Ooijen JW (2006) JoinMap® 4, Software for the calculation of genetic linkage maps in experimental populations. Kyazma BV, Wageningen, The Netherlands; 2006.

Voorrips RE (2002) MapChart: Software for the Graphical Presentation of Linkage Maps and QTLs. J Heredity 93 (1): 77-78.

Wang S, CJ Basten, and ZB Zeng (2005) Windows QTL Cartographer 2.5. Department of Statistics, NCSU, Raleigh, NC, 2005. [http:// statgen.ncsu.edu/qtlcart/WQTLCart.htm]. 
Wrather JA, TR Anderson, DM Arsyad, Y Tan, LD Ploper, A Porta-Puglia, HH Ram, and JT Yorinori (2001) Soybean disease loss estimates for the top ten soybean producing countries in 1998. Can J Plant Pathol 23: 115-121.

Wrather JA, AY Chambers, JA Fox, WF Moore, and GL Sciumbato (1995) Soybean disease loss estimates for the Southern United States, 1974 to 1994. Plant Dis 79: 1076-1079.

Wrather JA and SR Koenning (2006) Estimates of disease effects on soybean yields in the United States 2003 to 2005. J Nematol 38: $173-180$.
Wu X, S Blake, DA Sleper, JG Shannon, PB Cregan, and HT Nguyen (2009) QTL, additive and epistatic effects for SCN resistance in PI 437654. Theor Appl Genet 1 18: 1093-1 105.

Yue P, PR Arelli, and DA Sleper (2001a) Molecular characterization of resistance to Heterodera glycines in soybean PI 438489B. Theor Appl Genet 102: 921-928.

Yue P, DA Sleper, and PR Arelli (2001 b) Mapping resistance to multiple races of Heterodera glycines in soybean PI 89772. Crop Sci 41: 1589-1595. 